\title{
Influence of Work of Pregnant Women on Preterm Delivery: Case of Gécamines/Sud, Sendwe and Katuba Hospitals
}

\author{
Ngoie Mwana Nsapu Adelard, Ngomb Kazad Aline, Mwinkeu Kasongo Narcisse \\ Lubumbashi Nursing College, Lubumbashi, Democratic Republic of Congo \\ Email: narcissemk@yahoo.fr
}

How to cite this paper: Adelard, N.M.N., Aline, N.K. and Narcisse, M.K. (2018) Influence of Work of Pregnant Women on Preterm Delivery: Case of Gécamines/Sud, Sendwe and Katuba Hospitals. Open Access Library Journal, 5: e5029.

https://doi.org/10.4236/oalib.1105029

Received: November 5, 2018

Accepted: December 10, 2018

Published: December 13, 2018

Copyright ( 2018 by authors and Open Access Library Inc.

This work is licensed under the Creative

Commons Attribution International

License (CC BY 4.0).

http://creativecommons.org/licenses/by/4.0/

\begin{abstract}
The present study was an analytical referential case. It focused on 142 women giving birth and aimed to determine the proportion of preterm delivery among working women as well as the risk of giving birth prematurely as a hard-working woman. The results showed that the proportion of prematurity among working women was $89 \%$ with a risk of 6.2 times more than giving birth before term. This risk was exacerbated by malaria in pregnancy, urogenital infections and gestational diabetes.
\end{abstract}

\section{Subject Areas \\ Gynecology \& Obstetrics}

\section{Keywords}

Influence, Work of Pregnant, Preterm Delivery

\section{Introduction}

The threat of preterm delivery is at the forefront of pregnancy complications. It is one of the main causes of hospitalization during pregnancy [1]. The precarious social conditions of most families in the Democratic Republic of Congo push the pregnant woman to work restless times in order to meet family needs. Under these conditions, the pregnant woman is forced to travel long distances on foot or on a truck in search of daily food: a way to support the spouse who is often unemployed in our country. Added to this is the household work done without rest for lack of help. However, it is recommended that any pregnant woman should benefit from enough rest time for the good progress of the pregnancy in parallel even within the company; the recent evolutions of the world of 
work bring new forms of constraints and stress [2]. The number of women working outside the home continues to grow and we know that pregnant women work even with an old age pregnancy.

The hard work of the pregnant woman is a serious health problem that can compromise the good obstetric outcome especially by premature delivery. Prematurity is a major public health problem in both developed and developing countries because of its magnitude and strong association with childhood morbidity and mortality [3].

This work sets itself the objectives of determining the proportion of prematurity among working women as well as the risk of giving birth prematurely as a hard-working woman.

\section{Material and Method}

This referential case study was conducted for three months from $24^{\text {th }}$ April to $24^{\text {th }}$ July 2016. The study population consisted of 142 deliveries. In an exhaustive manner, this study included all maternal registered births during the survey period. Cases are women who gave birth prematurely. In the category of presentations, we selected any woman working outside the household or having an occupation that causes excessive fatigue.

The data were collected using a scale comprising the following variables collected from the delivering mothers met at GécaminesSud, Sendwe and Katuba hospitals: age, marital status, occupation, gestationalage, the condition of the child at birth, birth weight and pathologies during pregnancy.

We were able to obtain the free and informed consent of the delivering mothers after explaining the purpose of the study. The encoding and the processing of the data were done thanks to the software Epi info 3.5.4. (2012) and the results obtained were presented in tables.

In conducting this study, we noted that pregnant women who were under strict medical referral for one reason or another were not considered because they already had a threat of premature delivery.

\section{Results}

The average age was $26.8 \pm 7$ years with the modal age group of 29 - 33 years with $29.6 \%$ of cases. Early childbearing accounted for $14.8 \%$ of cases in the 14 to 18 age group (Table 1$)$.

Most respondents' mothers were married or $92.3 \%$ (Table 2).

The occupation of mothers exposing them to premature birth was the ambulatory sale of items (31\%), trading (21.8\%) and "various works" (20.4\%) (Table 3).

Average gestational age was $34 \pm 5.5$ weeks of amenorrhea with the modal age group of 37 - 41 S.A. with $33.9 \%$. However, $57.7 \%$ of premature births were recorded (Table 4).

The average birth weight was $2435 \pm 553$ grams with modal weight 1800 2300 grams with $48.6 \%$. However, $42.3 \%$ had a low birth weight (Table 5). 
Table 1. Distribution of mothers by age.

\begin{tabular}{ccc}
\hline Age (in years) & Number & $\%$ \\
\hline $14-18$ & 21 & 14.8 \\
$19-23$ & 26 & 18.3 \\
$24-28$ & 31 & 21.8 \\
$29-33$ & 42 & 29.6 \\
$34-38$ & 16 & 11.3 \\
$39-43$ & 6 & 4.2 \\
Total & 142 & 100 \\
\hline
\end{tabular}

Table 2. Distribution of mothers by marital status.

\begin{tabular}{ccc}
\hline Marital Status & Number & $\%$ \\
\hline Singles & 11 & 7.7 \\
Married & 131 & 92.3 \\
Total & 142 & 100 \\
\hline
\end{tabular}

Table 3. Distribution of mothers by occupation.

\begin{tabular}{ccc}
\hline Profession/Occupations & Number & $\%$ \\
\hline Doing various works & 29 & 20.4 \\
Housewife & 35 & 24.7 \\
Ambulatory sale of miscellaneous items & 44 & 31 \\
Teacher & 3 & 2.1 \\
Trading & 31 & 21.8 \\
Total & 142 & 100 \\
\hline
\end{tabular}

Table 4. Distribution of mothers by gestational age.

\begin{tabular}{ccc}
\hline Gestational age (in S.A.) & Number & $\%$ \\
\hline $22-28$ & 27 & 19 \\
$29-33$ & 21 & 14.8 \\
$34-36$ & 34 & 23.9 \\
$37-41$ & 48 & 33.9 \\
$>42$ & 12 & 8.4 \\
Total & $\mathbf{1 4 2}$ & Total \\
\hline
\end{tabular}

Table 5. Distribution of newborn babies by birth weight.

\begin{tabular}{ccc}
\hline Weight (in grams) & Number & $\%$ \\
\hline$<1200$ & 5 & 3.5 \\
{$[1200-1800]$} & 8 & 5.6 \\
{$[1800-2300]$} & 69 & 48.6 \\
{$[2300-3100]$} & 41 & 28.9 \\
{$[3100-3700]$} & 19 & 13.4 \\
Total & 142 & 100 \\
\hline
\end{tabular}


This table shows that during pregnancy, pregnant women suffered from urogenital infections at $49.3 \%$, malaria at $44.4 \%$, arterial hypertension at $11.3 \%$ and diabetes at $1.4 \%$ (Table 6 ).

In this category, we include all women who have an occupation outside the household with the result of excessive fatigue. Women with other occupations or working outside the household were 6.2 times more likely to give birth prematurely than housewives (Table 7).

Women workers with malaria during pregnancy were 4.9 times more likely to give birth prematurely than those who did not (Table 8).

Urinary infections during pregnancy did not influence the progress of pregnancy (Table 9).

Gestational diabetes has not been a factor in premature delivery (Table 10).

\section{Discussion}

The threat of preterm delivery (TPD) is the leading cause of hospitalization

Table 6. Distribution of respondents according to pathologies contracted during pregnancy.

\begin{tabular}{cc}
\hline Pathologies during pregnancy & $\%(\mathrm{~N}=\mathbf{1 4 2})$ \\
\hline Malaria & 44.4 \\
Urogenital infections & 49.3 \\
Gestational diabetes & 1.4 \\
Hypertension & 11.3 \\
None & 6.3 \\
\hline
\end{tabular}

Table 7. Relationship between woman's work and premature delivery.

\begin{tabular}{ccccc}
\hline & Premature delivery & Term birth & OR [IC to 95\%] & P \\
\hline Workingwomen $^{*}$ & $73(89 \%)$ & $34(56.7 \%)$ & $6.2[2.6-14.7]$ & 0.00001 \\
Housewives & $9(11 \%)$ & $26(43.3 \%)$ & & \\
Total & $\mathbf{8 2 ( 1 0 0 . 0 \% )}$ & $60(100.0 \%)$ & & \\
\hline
\end{tabular}

Table 8. Relationship between malaria in pregnancy and premature delivery.

\begin{tabular}{ccccc}
\hline & Premature delivery & Term delivery & OR (IC95\%) & P \\
\hline Malaria on pregnancy & $49(59.8 \%)$ & $14(23.3 \%)$ & $4.9[2.3-10.3]$ & 0.000017 \\
Malaria free & $33(40.2 \%)$ & $46(76.7 \%)$ & & \\
Total & $\mathbf{8 2 ( 1 0 0 . 0 \% )}$ & $\mathbf{6 0 ( 1 0 0 . 0 \% )}$ & & \\
\hline
\end{tabular}

Table 9. Relationship between urogenital infections and preterm delivery.

\begin{tabular}{ccccc}
\hline & Preterm delivery & Term delivery & OR (IC95\%) & P \\
\hline $\begin{array}{c}\text { Urinary infections } \\
\text { on pregnancy }\end{array}$ & $44(53.7 \%)$ & $26(43.3 \%)$ & $1.5[-0.77-2.96]$ & 0.22 \\
None & $38(46.3 \%)$ & $34(56.7 \%)$ & & \\
Total & $\mathbf{8 2 ( 1 0 0 . 0 \% )}$ & $60(100.0 \%)$ & & \\
\hline
\end{tabular}


Table 10. Relationship between gestational diabetes and premature delivery.

\begin{tabular}{ccccc}
\hline & Preterm delivery & Term delivery & OR (IC95\%) & P \\
\hline Gestational diabetes & $1(1.2 \%)$ & $1(1.7 \%)$ & $0.7[0.04-11.9]$ & 0.82 \\
None & $81(98.8 \%)$ & $59(98.3 \%)$ & & \\
Total & $82(100.0 \%)$ & $60(100.0 \%)$ & & \\
\hline
\end{tabular}

during pregnancy. It is complicated by preterm delivery in nearly $50 \%$ of cases [1]. In our study, the proportion of preterm delivery in the three health structures surveyed was $57.7 \%$ (Table 4). This rate is lower than those reported by Unicef [4] for Middle Eastern and developing countries [5] where low birth weight rates remain high. Low-birth-weight newborns predominate in our series at $42.3 \%$, which is relatively high compared to other Tunisian works and higher compared to foreign series where premature babies predominate. The frequency of premature infants in low birth weight is $33.8 \%$. This rate would be lower if twin pregnancies were excluded, where the frequency of prematurity is higher [4].

Our study found that 29- to 33-year-old women, $29.6 \%$, were more concerned with premature delivery. While a Quebec study conducted by researchers at CHU Sainte-Justine revealed that pregnant women aged 30 to 34 years would be those who have the least risk of giving birth prematurely [6].

The researchers also found that births before 37 weeks of pregnancy would be mostly spontaneous among young women aged 20 to 24 years. Without consensus, many studies have focused on the influence of the mother's age on the risk of premature delivery. Finally, in a large Canadian study of 165,000 women over the age of 20 in 32 urban and rural hospitals, the results indicate that their probability of having a premature baby is $5.7 \%$. In contrast, it is from the age of 40 that future mothers would be at greatest risk of giving birth before the $37^{\text {th }}$ week of pregnancy $(7.8 \%)$. In addition, this risk would be $6.8 \%$ for future mothers aged 20 to $24,6 \%$ for those aged 25 to 29 and $6.3 \%$ for women aged 35 to 39 . [6].

In our study, a link was established between the activities of pregnant women and premature delivery, $\mathrm{OR}=6.2$ and $\mathrm{p}=0.00001$. The housewife seemed to work less without the notion of intense fatigue because observing certain moments of rest. Other authors have shown an association between low socioeconomic status and preterm delivery [7]. Many factors are associated with low socio-economic status and preterm delivery (age, ethnic group, genital infections) and it is not easy to adjust for these confounding factors. An association between hard works, poor motivation or standing and preterm delivery has been highlighted by many authors [8]. These factors were retained in our study ( $\mathrm{p}=$ 0.00001 ) (Table 8). In addition, the literature associates stress at work with premature delivery. This highlights the interaction between psychological and professional factors. Paradoxically, the fact of not working has also been evidenced as a risk factor. However, this category served as witnesses for our study (house- 
wives). Other authors do not find these associations. Discrepancies in the results could be explained by incomplete control for confounding factors [9].

In particular, our study focused on women living mostly in precarious situations, with a low socioeconomic level. Focusing our study on diseases contracted during pregnancy, we have retained malaria $(\mathrm{p}=0.000017)$ related to premature delivery.

As for the age of pregnancy, the survey reveals that $38.7 \%$ of preterm delivery occurred between 29 - 36 weeks of amenorrhea. These results are very far from those of Cordier et al. who found that the majority of premature deliveries (94\%) occurred after 32 weeks. The risk factors common to both categories of prematurity are living without a spouse in the family and having a history of premature delivery. The risk factors specific to spontaneous prematurity are maternal age greater than 35 years, a history of episodes of urinary infections during pregnancy [10]. Only contrary to our results, only $7.7 \%$ of women were single.

According to Cordier et al. pregnancy-induced high blood pressure, gestational diabetes or asthma were the main risk factors for induced prematurity. Vaginal infections were not associated with an increased risk of prematurity [10]. On the contrary, a recent review estimates that infections during pregnancy, mainly vaginal infections, are responsible for $25 \%$ to $40 \%$ of premature deliveries [11]. Mulongo et al. showed that the main factors associated with preterm delivery were advanced maternal age ( $>35$ years), malaria, poor pregnancy monitoring, history of premature delivery, renal vascular syndrome, and urogenital infections [12]. These factors are avoidable to the maximum in order to reduce the risk of prematurity.

\section{Conclusions}

In the three health facilities surveyed, HGR Sendwe, Katuba and Gecamines/Sud Hospital, the work of the pregnant woman has a great influence on preterm delivery $(\mathrm{OR}=7.7)$. The rate of prematurity was $89 \%$ due to heavy loads carrying during the gestational period. Factors favoring preterm delivery were heavy load carrying (66.9\%), long walking (43\%), low back pain (39.4\%) and tiring work (36.6\%).

Pregnant education sessions should be reinforced during prenatal consultations on abstinence from heavy and tiring work in order to reduce the rate of premature delivery.

\section{Conflicts of Interest}

The authors declare no conflicts of interest regarding the publication of this paper.

\section{References}

[1] Ancel, Y. (2002) Threat of Preterm Delivery and Premature Labor with Intact Membranes: Physiopathology, Risk Factors and Consequences. Journal of Obstetric Gynecology and Reproductive Biology, 31. 
[2] Cortesao, M., Gonik, L. and Simon, M. (2012) What Are the Working Conditions That Influence Premature Delivery? Bachelor Thesis, HES.SO//Genève.

[3] Bwana Kangulu, I., Kilolo, N.U.E., Kabamba Nzaji, M. and Kalenga Mwenze, K.P. (2014) Low-Birthweight Risk Factors in Semi-Rural Kamina, Democratic Republic of Congo. Pan African Medical Journal, 17, 220.

[4] UNICEF (2016) Poverty, Illiteracy and Premature Death: According to UNICEF, This Is What Awaits the Most Disadvantaged Children of the Planet. UNICEF, New York.

[5] Newby, R. and Lovel, H. (1995) Low Birthweight at Kasaji Hospital, Zaire. Lancet, 346, 1493-1494. https://doi.org/10.1016/S0140-6736(95)92513-9

[6] Ouellet, M.C. (2018) Premature Delivery: Does the Age of the Mother Have an Impact? CHU Sainte-Justine, Agency-Science-Presse, Quebec.

[7] Berkowitz, G.S. and Papernik, E. (1993) Epidemiology of Pretermbirth. Epidemiologic Reviews, 15, 414-443.

https://doi.org/10.1093/oxfordjournals.epirev.a036128

[8] Mamelle, N., Bertucat, I. and Munoz, F. (1989) Pregnant Women at Work: Rest Periods to Prevent Preterm Birth? Paediatric and Perinatal Epidemiology, 3, 19-28. https://doi.org/10.1111/j.1365-3016.1989.tb00366.x

[9] Epiney, M., Boulvain, M. and Irion, O. (2018) Psychosocial Risk Factors and Premature Delivery. Revue Médicale Suisse, 7, 2066-2069.

[10] Cordier, S., Kadhel, P., Rouget, F. and Multigner, L. (2014) Risk Factors for Prematurity in Guadeloupe: Results of the Timoun Cohort. IRSET, Rennes 1 University, Rennes.

[11] Goldenberg, R.L., Culhane, J.F., Iams, J.D. and Romero, R. (2008) Epidemiology and Causes of Preterm Birth. Lancet, 371, 75-84.

https://doi.org/10.1016/S0140-6736(08)60074-4

[12] Twins, B. (2016) Premature Babies: What Are the Causes of Premature Birth? https://le-mag.radins.com/dossiers/bebe/bebe-premature-quuelles-sont-les-causesd-une-naissance-avant-terme,3457.html 